\title{
The Effect of a Virus on Adult Development
}

\author{
Peter Martin ${ }^{1}$ \\ Published online: 26 May 2020 \\ (c) Springer Science+Business Media, LLC, part of Springer Nature 2020
}

As the editor for the Journal of Adult Development, I feel that I should not ignore the unprecedented changes and challenges we are experiencing in the United States and all over the world. It seems a bit premature to sort out all the implications and effects that the COVID-19 pandemic has on adult development. On the other hand, we are called upon as scholars, researchers, and teachers to begin reflecting on the physical, social, and psychological effects and the drain of resources such an epidemic might have on many people.

I will not speculate what specific short- and long-term effects there will be, but let me outline a few topics that appear relevant to adult development. The first issue coming to mind concerns the effect on young adults in emerging adulthood. There is great uncertainty about the future trajectory for young adults. Young adults may feel they are stopped in their tracks as they want to transition from high school to a job or to college. Others now face collegelevel classes online, and college graduates are wondering where to find a job, or they may be facing other unexpected developmental tasks. In his seminal work on the children of the Great Depression (Elder 1974), Glen Elder has written extensively about the effect of historical events. Likewise, Conger et al. (2004) reflected on the effect of the farm crisis in the Midwest of the United States. Some of the trajectories for young adults are going to be changed forever by the COVID-19 pandemic.

Similarly, individuals in midlife are also be affected by the COVID-19 pandemic. People who had good jobs that paid a reasonable living wage may now be uprooted if they have been unexpectedly laid off. Some individuals and families live "paycheck to paycheck," and the current crisis surely has an effect on the developmental transition during the midlife years. Health care providers in midlife see critical cases every day, including individuals who succumb to

Peter Martin

pxmartin@iastate.edu

1 Iowa State University, 1096 LeBaron Hall, 626 Morrill Rd, Ames, IA 50011-2100, USA the effects of the virus. Their experiences most likely shape their perspective on life and death.

Older adults can be significantly affected, as they are often mentioned as belonging to a "risk group," more likely to experience the negative consequences of the corona crisis. The case-fatality rate for COVID-19 is estimated at 3\% to $5 \%$ for people $65-74$ years of age and increases to about $10-27 \%$ for people 85 years and older (Le Couteur et al. 2020). With this relatively high fatality rate, older adults can easily be targeted and labeled as vulnerable. However, older adults belong to a very diverse group — some have serious chronic health problems that would make them more susceptible to negative outcomes, but others remain healthy and active. Although the risk for older adults to contract COVID-19 is high, it must be noted that severe infections and significant mortality occur across the entire life course (Le Couteur et al. 2020). There is a possibility that during this pandemic old stereotypes reinforcing ageist perceptions are revived (Ayalon et al. 2020).

It is not age that predicts the disease trajectory for older adults; it is the chronic health condition, a compromised immune system, or living in a residential facility that may affect older more than younger adults. Furthermore, we should not talk about older adults but rather give this age group a voice in their own matters. The Gerontological Society of America has launched The Reframing Aging Initiative (Gerontological Society of America 2020) that underlines the importance of understanding inclusive language when communicating about COVID-19.

As we reflect on different age groups, we should place a focus on development in the context of families and communities. Given stay-at-home policies, intergenerational ties are restricted, and the overall solidarity among parents, grandchildren, children, and grandchildren may be compromised. When younger adults get the impression that they are to stay at home to keep older adults safe, intergenerational resentment may ensue. Comparing active and productive younger adults to frail and vulnerable older adults does not help either generation come to terms with this crisis. 
Such views may underline negative images of aging among younger adults (Ayalon et al. 2020).

It is obvious that the COVID-19 challenge can have severe effects on developmental outcomes. As people get more frustrated over time, they may experience increased negative emotions, and these emotional experiences may be more difficult to regulate. Because of restrictions in movement, more loneliness or social isolation may occur. There is more of a risk for domestic abuse. In addition to these psychological and behavioral effects, we can also expect changes in physical health. As visiting a health practitioner is more limited and people feel more restricted at home (with heightened stress levels, limited physical exercise, less emphasis on good nutritional habits and disrupted sleep patterns), the pandemic may result in lasting effects on adult development (Schrack et al. 2020).

However, the stress and trauma literature points out that individuals of all ages, families, and communities can counter such effects and show healthy levels of resilience (Masten 2001; Norris and Stevens 2007; Walsh 2015). Personal resilience refers to individual strength, personality, control, and the ability to use cognitive and behavioral strategies to deal with stressful situations effectively. Family resilience refers to optimal communication patterns and family cohesiveness during a time of crisis. Resilient communities develop environmental plans that allow people to feel safe when adversity hits. Studies suggest that negative perceptions are associated with loneliness and psychological distress, whereas positive self-perceptions of aging are associated with more resilience during the COVID-19 outbreak (Losada-Baltar et al. 2020).

We are currently experiencing unprecedented changes caused by a highly contagious virus. As scholars, we are challenged to observe, investigate, and research the effects of such a crisis. I expect that our journal will receive manuscripts that clarify the developmental impact on young adults, midlife, and older adults. I invite scholars in our field to submit articles on this important topic. I welcome quantitative and qualitative papers, and I am also open to theoretical or conceptual papers on the subject. We will fast track appropriate manuscripts that highlight how pandemics and other national crises affect the development of adults of all ages. The virus is a challenge-we must learn how to respond to difficulties effectively and how to integrate lessons learned into the course of adult life.

\section{References}

Ayalon, L., Chasteen, A., Diehl, M., Levy, B. R., Neupert, S. D., Rothermund, K., et al. (2020). Aging in times of the COVID-19 pandemic: Avoiding ageism and fostering intergenerational solidarity. Journal of Gerontology Series B. https://doi.org/10.1093/ geronb/gbaa051.

Conger, R. D., Lorenz, F. O., \& Wickrama, K. A. S. (Eds.). (2004). Continuity and change in family relations: Theory, methods, and empirical findings. Mahwah, NJ: Erlbaum.

Elder, G. (1974). Children of the great depression: Social change in life experience. Chicago: University of Chicago Press.

Gerontological Society of America. (2020). Reframing aging initiative. Retrieved May 23, 2020 from https://www.geron.org/programsservices/reframing-aging-initiative.

Le Couteur, D. G., Anderson, R. M., \& Newman, A. B. (2020). COVID-19 through the lens of gerontology. Journal of Gerontology Series A. https://doi.org/10.1093/gerona/glaa077.

Losada-Baltar, A., Jiménez-Gonzalo, L., Gallego-Alberto, L., del Pedroso-Chaparro Sequeros, M., Fernandes-Pires, J., \& MárquezGonzález, M. (2020). We are staying at home. Association of self-perceptions of aging, personal and family resources, and loneliness with psychological distress during the lock-down period of COVID-19. Journals of Gerontology, Series B. https://doi. org/10.1093/geronb/gbaa048.

Masten, A. S. (2001). Ordinary magic: Resilience processes in development. American Psychologist, 56, 227-238. https://doi. org/10.1037/0003-066X.56.3.227.

Norris, F. H., \& Stevens, S. P. (2007). Community resilience and the principles of mass trauma intervention. Psychiatry Interpersonal \& Biological Processes, 70, 320-328. https://doi.org/10.1521/ psyc.2007.70.4.320.

Schrack, J. A., Wanigatunga, A. A., \& Juraschek, S. P. (2020). After the COVID-19 pandemic: The next wave of health challenges for older adults. Journals of Gerontology Series A. https://doi. org/10.1093/gerona/glaa102.

Walsh, F. (2015). Strengthening family resilience. New York: Guilford Publications.

Publisher's Note Springer Nature remains neutral with regard to jurisdictional claims in published maps and institutional affiliations. 